\title{
Improved tympanic membrane regeneration after myringoplastic surgery using an artificial biograft
}

\author{
A.P.S. Immich ${ }^{\text {a }}$, P.C. Pennacchi ${ }^{\text {b }}$, A.F. Naves ${ }^{\text {a }}$, S.L. Felisbino ${ }^{c}$, R.L. Boemo ${ }^{\mathrm{d}}$, S.S. Maria-Engler ${ }^{\text {b }}$, L.H. Catalani ${ }^{\text {a,* }}$ \\ a Departamento de Química Fundamental, Instituto de Química, Universidade de São Paulo, São Paulo, Brazil \\ b Departamento de Análises Clínicas e Toxicológicas, Faculdade de Ciências Farmacêuticas, Universidade de São Paulo, São Paulo, Brazil \\ ' Departamento de Morfologia, Instituto de Biociências de Botucatu, Universidade Estadual Paulista “Júlio de Mesquita Filho", Botucatu, Brazil \\ d Centro de Otorrinolaringologia e Fonoaudiologia de São Paulo, Complexo Hospitalar Edmundo Vasconcelos, São Paulo, Brazil
}

\section{A R T I C L E I N F O}

\section{Article history:}

Received 15 April 2016

Received in revised form 24 October 2016

Accepted 4 December 2016

Available online 6 December 2016

\section{Keywords:}

Biomimetic material

Cell culture

Fibroblast

Keratinocyte

In vivo test

Poly (lactic-co-glycolic acid)

\begin{abstract}
A B S T R A C T
Tympanic membrane perforations are due to common otologic problems. The current treatments to heal tympanic membrane perforation, such as myringoplasty, have some disadvantages, including the need for autologous grafting, which is rapidly absorbed by the organism before perforation recovery is complete. To improve the structural and functional tympanic membrane healing after surgery, we propose a new branch of artificial grafts. In this study, we report the development of artificial grafts using electrospun bioabsorbable polymers. Polymers such as poly (L-lactic acid) and poly (lactic-co-glycolic acid) acted as the scaffold for cell growth in a co-culture of fibroblasts and keratinocytes. This co-culture promoted the growth of an epithelial-equivalent tissue over the electrospun scaffold, which was used as an alternative graft in myringoplasty. The in vivo study was performed in Sprague Dawley rats. Ear endoscopy was performed 30 days after surgery and showed that tympanic membrane perforations treated with artificial grafts healed naturally, completely and with the possibility of maintaining their actual functionality. In conclusion, our study described a new artificial graft created specifically to fulfill the requirements of perforated tympanic membrane healing processes, which are compatibility, proper durability and less intense side effects following myringoplasty.
\end{abstract}

(c) 2016 Elsevier B.V. All rights reserved.

\section{Introduction}

Tympanic membrane (TM) perforation is a frequent pathology of varied etiology; perforation can be traumatic, infectious or residual from transtympanic drainage $[1,2]$. Audiological manifestations of a tympanic perforation may include conductive hearing loss with, tinnitus, ear fullness and otorrhea may also occur [3,4]. The location and size of the perforation and the frequency of hypoacusis (partial hearing loss) generally depend on the infectious agent and the severity of the condition; and hearing loss is a dependent variable of tympanic perforation chronicity [5].

Tympanic membrane treatment aims to heal perforations of the tympanic tissue to eradicate the disease, restore the tympanic aeration, reconstruct the sound-transformer mechanism and create a dry, self-cleaning cavity [6]. Many procedures and materials have been used to attempt closure of tympanic perforations. The literature has focused on two major research themes. The first includes the healing of perforations through new polymer matrices that promote support and serve as a guide for tissue regeneration, using myringoplasty surgery [3,4]. The second aims to induce cell proliferation and migration using mitogen (growth modulating

\footnotetext{
* Corresponding author.

E-mail address: catalani@usp.br (L.H. Catalani).
}

factors) or inducers of blood flow (hemorrheologic agents) [1,7,8]. Currently, myringoplasty or tympanoplasty is the most accepted method. However, relapses are observed in up to $30 \%$ of cases [9].

In 1878, Berthold [10] introduced the term myringoplasty to describe the use of a free skin graft to close a perforation. The creators of the current myringoplasty procedure are Zöllner and Wülstein [11], who proposed a classification of surgical procedures based on the location of the graft related to auditory ossicles or the windows of the cochlea. In 1960, Hermann described the use of autologous temporalis fascia grafts to treat tympanic membrane perforation $[12,13]$. At this time, Goodhill used tragus perichondrium to achieve similar results [14,15]. In 1964, Salen [16] was the first to use nasal septum cartilage as graft material. In 2009, Uçar and Kazkayasi [17] used perichondrium from the nasal septum to repair tympanic membrane perforation. The characteristics and the ease of handling of these grafts meant that the materials are still the most frequently used to repair tympanic defects. However, numerous techniques have been described; the search for the best results continues, from both an anatomical and a functional perspective.

Classical myringoplasty using autologous grafts has certain disadvantages. The most important disadvantages are as follows: the self-implanted tissue has a short lifespan, which may be insufficient to allow complete tympanic regeneration, and serves exclusively as a support to the new cells that may develop over the graft, since the fascia tissue 
does not grow by itself; the need to extract tissues from the patient; and, in general, hearing is not sufficiently recovered in $40 \%$ of cases [18]. Insufficient auditory recovery is likely due to the abnormal process of tympanic membrane healing and injury to the ossicles, which are located just underneath where healing occurs.

In recent years, major advances in tissue engineering and regenerative medicine have facilitated the search for new biocompatible and bioabsorbable materials, the so called polymeric scaffolds for cell growth [19-21]. This materials developed in laboratories can be used in the reconstruction of bone defects, in the repair of organs affected by disease, and can replace animal tissues used in in vivo testing [22-25]. This new category of materials could find an important application in classic myringoplasty as a better alternative to autologous grafting, once it is possible to recreate all layers that constitute the real tympanic membrane, allowing appropriate functional and anatomical results of the regenerated tympanic membrane.

In tissue engineering, polymeric grafts mimic the extracellular matrix of the tissue on demand, promoting adhesion, cell growth and proliferation. The advantages of these new polymeric grafts are as follows: longevity, which allows for better tympanic regeneration; less inflammatory reactions; elimination of the need to extract patient's tissue to serve as a graft; the facilitation of shorter and simpler interventions that can be performed in a clinic or physician's office; and a structure more similar to natural tympanic membrane, which can improve the recovery of hearing loss.

Teh et al. [26] studied different scaffolds for tympanic membrane regeneration in rats, such as silk fibroin scaffold (SFS) and porcine-derived acellular collagen type I/III scaffold (ACS), compared with two commonly used graft materials, paper patch and Gelfoam. This study showed that both SFS and ACS significantly accelerated acute tympanic membrane wound healing and achieved hearing recovery from an early stage. In contrast, paper patch and Gelfoam lost their scaffold function in the early stages and showed an inflammatory response, which may have contributed to delay in healing. Lee [27] also studied silk fibroin as a biomaterial and the results showed this material displays excellent longterm degradation behavior, which could be an issue when rapid degradation is required, such as for tympanic membrane recovery purposes. Levin et al. [7] also investigated the growth of human tympanic membrane keratinocytes on a scaffold composed of silk fibroin. The results indicated that the biomaterial supported the growth and proliferation of these keratinocytes and silk fibroin scaffolds may enable otological surgeons to successfully close chronic tympanic membrane perforations.

A nonsurgical alternative to treat perforated tympanic membrane was studied by Seonwoo et al. [28]. They used an EGF-releasing chitosan patch for the regeneration of chronic tympanic membrane perforation. Although EGF-CPSs enhanced cell viability and the healing rate of chronic TM perforations compared to spontaneous healing, the healing rate of the EGF-CPS method did not reach those of surgical methods. For this reason, they concluded the treatment could be used for patients suffering less severe chronic tympanic membrane perforations with sizes up to $50 \%$ of tympanic membrane. Hence, there is a constant search for better materials to achieve improved healing and hearing.

To fulfill the requirements for tissue regeneration, we developed a tissue-engineered device known as biograft. This biograft was based on electrospun polymeric scaffolds used for cell growth and tissue differentiation. The aim is to repair perforated tympanic membrane through implantation of the biograft after tympanic membrane injury. The healing process with the developed artificial graft is expected to promote improved healing with fewer side effects after myringoplasty.

\section{Materials and methods}

\subsection{Materials and cell sources}

Poly (L-lactic acid) (PLLA; IV $3.2 \mathrm{dl} / \mathrm{g}, \mathrm{M}_{\mathrm{w}} 216,000 \mathrm{~g} / \mathrm{mol}$ ) and poly (lactic-co-glycolic acid) 50:50 (PLGA; IV $1.0 \mathrm{dl} / \mathrm{g}, \mathrm{M}_{\mathrm{w}}$ 110,000 g/mol) were supplied by PURAC (Netherlands). Chloroform and dimethylformamide were supplied by Synth (Brazil).

The cell types studied were fibroblasts and keratinocytes. Both cells were supplied by the Clinical Cytopathology Laboratory at the School of Pharmaceutical Sciences at the University of São Paulo, Brazil. Keratinocytes and fibroblasts were isolated from the foreskin of infants and children up to 10 years who underwent circumcision surgery at the University Hospital of the University of São Paulo (Brazil). The rules of the local ethics committee, under registration $n^{\circ}$ CEP-HU/USP 943/09, SISNEP CAAE 0062.0.198.000-9, were followed.

\subsection{Methods}

\subsubsection{Polymeric scaffold preparation}

PLLA, PLGA, and mixtures of PLLA and PLGA (at ratios of 75:25, 50:50, and 25:75) were solubilized in chloroform under constant magnetic agitation for $24 \mathrm{~h}$. After complete solubilization, $10 \%$ of dimethylformamide was added to a final concentration of $100 \mathrm{~g} / \mathrm{l}$.

The scaffolds were produced from non-woven mats of PLLA/PLGA blends, obtained using electrospinning technique under the following conditions: solution flow rate of $2 \mathrm{ml} / \mathrm{min}$; applied voltage of $25 \mathrm{kV}$; and capillary/collector distance of $15 \mathrm{~cm}$. After electrospinning, the scaffold was suitably packaged in a vacuum desiccator for complete solvent evaporation. The resulting scaffolds were modeled according to the dimensions of the human tympanic membrane, or $8-10 \mathrm{~mm}$ in diameter and 30-90 $\mu \mathrm{m}$ thick [18].

Differential scanning calorimetry (DSC) analyses were performed in a TA Instruments DSC Q-10 calorimeter. DSC curves were typically obtained by heating $5-10 \mathrm{mg}$ of material $\left(10{ }^{\circ} \mathrm{C} / \mathrm{min}\right)$ from -20 to $200{ }^{\circ} \mathrm{C}$. This was followed by cooling $\left(20^{\circ} \mathrm{C} / \mathrm{min}\right)$ and heating $\left(10^{\circ} \mathrm{C} /\right.$ $\mathrm{min}$ ) in a $\mathrm{N}_{2}$ atmosphere with a flow rate of $50 \mathrm{ml} / \mathrm{min}$. The second heating curve was used for characterization.

The degradation tests were performed in vitro according to the international standard ISO 13781: "Poly(L-lactide) resins and fabricated forms for surgical implants - In vitro degradation testing". The membranes were analyzed after incubation periods of $2,4,8,10$, and 12 weeks in phosphate buffered saline solution at $37{ }^{\circ} \mathrm{C}$ and $\mathrm{pH}$ 7.4. Size exclusion chromatography (SEC) and scanning electron microscopy (SEM) were used to analyze the degradation of membranes. Samples of dried membranes were used for the tests. Measurements of $\bar{M}_{n}, \bar{M}_{w}$, and the polydispersity index (PDI) were performed using a Malvern/ Viscotek GPC system composed by GPCmax and TDA-305-040 modules fitted with the three Viscotek T6000 M columns. The mobile phase was chloroform with a flow rate of $0.5 \mathrm{ml} / \mathrm{min}$.

The surface energy of the thin spin coated films was determined by means of the contact angle measurements by applying the sessile drop method. Milli-Q water and diiodomethane (Sigma) were used for the liquid tests (drops of $10 \mu \mathrm{l}$ ). Hysteresis of contact angle $(\Delta \theta)$ was determined by measuring the advancing $\left(\theta_{\mathrm{A}}\right)$ and receding $\left(\theta_{\mathrm{R}}\right)$ contact angles with water drops of 10 and $5 \mu$, respectively. Contact angle values were evaluated using the public domain software program Image $1.49 \mathrm{k}$. Spin-coated films (Headway PWM32-OS-RT90 spin coater) prepared from membranes solutions $(10 \mathrm{mg} / \mathrm{ml})$ in chloroform were deposited on $\mathrm{Si} / \mathrm{SiO} 2$ wafers $\left(1 \mathrm{~cm}^{2}\right)$ at $3000 \mathrm{rpm}$. Film thicknesses were monitored by ellipsometry (Ratzeburg DRE-EL02) using a He-Ne laser (632.8 nm) at an incidence angle of $70^{\circ}$. The refractive index was considered to be constant $(\eta=1.465)$, and the deposited film was uniform and isotropic.

For in vitro and in vivo studies, the membranes were sterilized by immersion in 70\% ethanol for $24 \mathrm{~h}$. This was followed by UV-C irradiation for 20 min on each side.

To verify mechanical properties of the polymeric blend, tensile tests were carried out in a Stable Micro systems texture analyzer, Model: TAHD-Plus, test speed of $1 \mathrm{~mm} / \mathrm{s}$, with a cell load of $50 \mathrm{Kg}$. The specimen dimensions used in the test were $5 \mathrm{~cm}$ in length, $3 \mathrm{~cm}$ in width and $300 \mu \mathrm{m}$ in thickness. The test was repeated 10 times. 


\subsubsection{In vitro studies}

Fibroblasts and keratinocytes were grown in a cell culture incubator at $37^{\circ} \mathrm{C}$ in a 24 -well plate containing normal growth medium specific for each lineage. Cells were maintained in $\mathrm{CO}_{2}$ atmosphere, which was suitable for maintaining a $\mathrm{pH}$ close to the physiological value. Keratinocyte cultures were maintained in atmosphere of $7.5 \% \mathrm{CO}_{2}$ in KGM Gold BulletKit medium (KBM-Gold Keratinocyte Basal Medium Gold without $\mathrm{Ca}$, Lonza) supplemented with KGM-Gold SingleQuot Kit (Lonza) plus isoproterenol 10-6 M (Sigma) [29]. Fibroblasts were maintained in DMEM (Gibco) supplemented with $10 \%$ fetal bovine serum (Gibco) and antibiotics (100 U/ml ampicillin and $100 \mathrm{~g} / \mathrm{ml}$ of streptomycin - LifeTechnologies). The fibroblast cell culture was maintained in a humidified atmosphere containing $5 \% \mathrm{CO}_{2}$. Cells were subcultivated when approximately $80 \%$ of the saturation density was reached. Subcultivation was carried out using 0.1\% trypsin in PBS (phosphate buffered saline containing 1 mM EDTA - ethylene diamine tetra-acetic acid); the cell culture was always prewashed with the same buffer solution. Cell stocks were maintained in culture medium containing the cryoprotectant DMSO (dimethyl sulfoxide) up to $8 \%$ at $-196{ }^{\circ} \mathrm{C}$ in a reservoir containing liquid nitrogen.

2.2.2.1. Epidermis production. The electrospun membranes were modeled to be similar in shape to the tympanic membrane with $10 \mathrm{~mm}$ in diameter. The electrospun membranes were sterilized with $70 \%$ ethanol for $24 \mathrm{~h}$ and irradiated with UV-C light (according to item 2.2.1). After sterilization, the membranes were fixed in a transwell permeable support, which was placed in a 12-well plate and soaked with DMEM for $48 \mathrm{~h}$ to complete hydration, to be used as a scaffold for cell culture.

The cell culture was divided into the following two phases: (i) the construction of a dermal-equivalent layer through fibroblast culture, followed by (ii) the construction of an epidermal-equivalent layer on top via keratinocyte seeding and culture. For the production of a dermal-equivalent layer, $10^{5}$ fibroblasts were seeded on the surface of the polymeric membrane in D-10 medium (DMEM with $10 \%$ fetal bovine serum, FBS) and incubated at $37{ }^{\circ} \mathrm{C}$ in a $5 \% \mathrm{CO}_{2}$ atmosphere. After $24 \mathrm{~h}, 2.5 \times 10^{5}$ keratinocytes were seeded on top of the dermal equivalent for the production of the epidermis equivalent. Keratinocytes were seeded in a 1:1 mixture of keratinocyte cultivation medium and raft medium (a special medium to promote the stratification of the epidermis) and incubated at $37{ }^{\circ} \mathrm{C}$ in $5 \% \mathrm{CO}_{2}$ [29]. After $24 \mathrm{~h}$ of keratinocyte adhesion, the transwell containing the cultivated membrane was transferred to a deepwell plate and maintained at an air-liquid interface containing Raft medium for 12 days. The raft medium and the air-liquid interface stimulate stratification and tissue formation.

The RAFT medium used for maintaining the epidermal equivalent is composed of DMEM and Ham F12 medium in a 3:1 ratio. The Raft medium also contains $10 \%$ FBS supplemented with choleric toxin (10.1 nM), insulin $(5 \mu \mathrm{g} / \mathrm{ml})$, apo-transferrin $(5 \mu \mathrm{g} / \mathrm{ml})$, hydrocortisone-21 hemisuccinate $(0.4 \mu \mathrm{g} / \mathrm{ml})$ and epidermal growth factor $(0.5 \mathrm{ng} / \mathrm{ml})$.

After 12 days of culture in Raft medium, the membranes were removed and fixed in buffered formalin (10\% formaldehyde in buffer) at $4{ }^{\circ} \mathrm{C}$ for $1 \mathrm{~h}$. Membranes were then sent for histological processing.

For the histological analyses, the samples were dehydrated in ethanol (via increasing concentrations), cleared by xylene, and impregnated and embedded in blocks of histological paraffin. The blocks were cut in a microtome (American Optical Corporation, model 820) set to $5 \mathrm{m \mu}$. The sections were stained with hematoxylin-eosin (HE). An optical microscope coupled to a camera was used to examine the sections.

2.2.2.2. Immunohistochemistry for CK10 and CK14. Immunohistochemical assays were performed to verify that the differentiation of reconstructed epidermis on the polymer membrane mimicked the human tympanic membrane. Samples were analyzed with markers of cellular differentiation. The antibody anti-keratin 10 (CK10 - clone VIK-10 Abcam code ab1421) is reactive to stratified and highly differentiated epithelium, and the anti-keratin 14 antibody (CK14 - Abcam code ab7800 clone LLO02) is responsive to the proliferation and stratification of the basal layer of the epithelium [29]. The antibodies were used in the final dilution $v / \mathrm{v}$ as follows: Anti-cytokeratin 10 in 1:150; and Anticytokeratin 14 in 1:300.

2.2.2.3. Immunohistochemistry for Ki-67. Sections of $4 \mu \mathrm{m}$ of the reconstructed epidermis on the polymer membrane were collected on silanized glass. Antigen retrieval was achieved using a decloaker for $20 \mathrm{~min}$. After washing, the slides were blocked with $3 \%$ hydrogen peroxide in methanol for 10 min followed by $3 \%$ bovine serum albumin (BSA) in PBS for $1 \mathrm{~h}$ at room temperature. Slides were then incubated with rabbit polyclonal anti-Ki-67 antibody (\#ab15580, ABCAM, CA, USA) at a 1:100 dilution in $1 \% \mathrm{BSA}$ in PBS and incubated overnight at $4{ }^{\circ} \mathrm{C}$. After washing with PBS, the slides were incubated for $1 \mathrm{~h}$ at room temperature with goat anti-rabbit IgG-HRP antibody (Santa Cruz Biotechnology, CA, USA) diluted 1:200 in 1\% BSA in PBS. Chromogen colour development was carried out with 3.3'-diaminobenzidine tetrahydrochloride, slides were counterstained with Harris's hematoxylin. Negative control was performed by omitting the primary antibody incubation step.

2.2.2.4. Cytotoxicity assay. To evaluate the cytotoxic effect of polymer degradation products, the D-10 medium (D-MEM supplemented with $10 \%$ FBS) used in cell culture was previously aged, being kept in contact with the electrospun polymeric membrane for 35 days at $37{ }^{\circ} \mathrm{C}$ and $5 \%$ $\mathrm{CO}_{2}$. Then, fibroblasts were seeded in 24 -well plates $\left(3 \times 10^{5}\right.$ cells per well) and maintained in the aged D-10 medium. The objective of using an aged D-10 medium was to verify any harmful product possibly released by the electrospun membrane degradation. Cell viability assays were performed $24 \mathrm{~h}$ after culturing. Fibroblasts were also seeded in normal D-10 medium as control. Trypan Blue exclusion test for cell viability determination was used and the experiment was performed in triplicate.

\subsubsection{In vivo studies}

Every surgical procedure was performed according to the ethical principles of animal experimentation adopted by the National Council for the Control of Animal Experimentation (CONCEA) and was approved by the Ethics Committee on Animal Use (CEUA) at the Institute of Chemistry at the University of São Paulo with certificate number 12/2013. During all surgical procedures, including aseptic ear and control inspections, the animals were sedated by intramuscular injection of acepromazine ( $1 \mathrm{ml} / \mathrm{kg}$ of the animal), ketamine $(0.6 \mathrm{ml} / \mathrm{kg})$ and xylazine $(0.5 \mathrm{ml} / \mathrm{kg})$. Acepromazine is a pre-anesthetic that was administered 10 min before the administration of ketamine and xylazine.

The fifteen adult male rats $(n=15)$ selected for the experiments were of the same lineage (Sprague Dawley) and bred in the vivarium of the Institute of Chemistry of the University of São Paulo. Rats were randomly divided into three groups. For the control group (group 1), only the plain polymer membrane without cell culture was implanted. In the second group (group 2), the electrospun membrane construct with epidermal-equivalent tissue was implanted. In the third group (group 3), the electrospun membrane construct with epithelial-equivalent tissue was implanted. All rats were observed in separate cages with free access to food and water throughout the experiment.

Otologic surgical techniques were performed in two consecutive steps in the same surgical intervention. First, a traumatic and subtotal iatrogenic myringotomy (a tympanic perforation caused intentionally that is greater than $40 \%$ of the size of the intact tympanic membrane) was performed in both ears. Perforation was performed using a cold otologic surgical knife under an optical microscope. After the bilateral myringotomy, a transcanal myringoplasty was performed on the right ear according to the classification of Wülstein [11]. The artificial grafts were implanted in the right ear to recover the perforated tympanic 
membrane. The left ear was left without myringoplasty treatment and healed spontaneously as a comparative healing control. Inspection of the perforated tympanic membrane of each animal was performed 30 days after the operation. The control was carried out in an otologic otoscope coupled to a computer for image capture.

After the recovered, tympanic membrane were inspected, the animals were sacrificed in a $\mathrm{CO}_{2}$ atmosphere with a flow rate of $7 \mathrm{l} / \mathrm{m}$. After the deaths were verified, animals were decapitated. Both external ears were separated on the osteocartilaginous junction, and the tympanic membrane was fixed in $10 \%$ buffered formalin for $12 \mathrm{~h}$. After fixation, the specimens were dehydrated in an increasing ethanol gradient. The removed tissue was embedded in histological paraffin and cut into horizontal sections with thicknesses varying from 4 to $6 \mu \mathrm{m}$. Each section was stained with hematoxylin-eosin and examined under a light microscope coupled to a computer system for image analysis.

\section{Results and discussion}

The complete study was divided into the following three stages: the production of the polymeric scaffold, the in vitro stage and the in vivo stage. The scaffold was produced using an electrospinning technique. In the in vitro stage, epithelial-equivalent tissue was produced on the polymeric scaffold to compose the artificial graft. The in vivo stage consisted of the surgical procedure for the implantation of the artificial graft. The artificial graft was implanted in the rats for tympanic regeneration, and posterior histological studies of the regenerated tissue were performed.

\subsection{Polymer scaffold preparation and characterization}

The main purpose of the polymers used in this study was to provide support and guidance for epithelial-equivalent tissue growth when implanted in humans to repair tympanic membrane perforations. Therefore, the proper choice of material can determine the success of the tympanic recovery. Materials with short degradation times may be reabsorbed by the body before the closure of the perforation. Longlived materials can remain in the region after tympanic healing, undermining the recovery of hearing.

The polymers were selected based on their durability against degradation processes simulated in the laboratory. The polymers chosen for testing were PLLA and PLGA, which are all approved by the USFDA (Food and Drug Administration) due to their biodegradability and biocompatibility. These polymers were subjected to biodegradability tests according to the international standard ISO 13781; scaffolds were analyzed after incubation of 12 days (period needed for epidermis production to be complete) in phosphate buffered saline solution at $37^{\circ} \mathrm{C}$. The mass loss measured by chromatography after 12 days of analysis were $7 \%$ for PLLA, $72 \%$ for PLGA. It is known that PLLA has a durability that may extend from 6 months to 2 years; this is due to its semi-crystalline structure, which explains its low mass loss. PLGA, being completely amorphous, had low durability and higher rate of mass loss [30].

According to these observations, the best electrospun membrane to fulfill our requirements would be a membrane with an intermediate degradation behavior between PLLA and PLGA. For this reason, polymers blends were produced by solvent casting in the following proportions: PLLA/PLGA in ratios of 25:75, 50:50, and 75:25. It was, therefore, possible to find intermediate degradation behavior between the two polymers to adjust the requirements of the biograft.

To verify the durability of different blends, the membranes were immersed in buffer solution (PBS) at pH 7.4 and maintained at $37^{\circ} \mathrm{C}$ for 2,4 , 8,10 , and 12 weeks, according to the international standard ISO 13781. Before the degradation tests, the electrospun scaffold presented molecular weight and PDI values that were intermediate of the ones measured for PLLA $\left(\bar{M}_{w}=216.000 \mathrm{~g} / \mathrm{mol}\right.$, PDI $\left.=1.3\right)$ and PLGA $\left(\bar{M}_{w}=\right.$ $110.000 \mathrm{~g} / \mathrm{mol}, \mathrm{PDI}=2.3$ ). The apparent molecular weight of the blends were determined as $\bar{M}_{w}=170.000 \mathrm{~g} / \mathrm{mol}, \mathrm{PDI}=2.2$ for $75: 25, \bar{M}_{w}=$ $150.000 \mathrm{~g} / \mathrm{mol}, \mathrm{PDI}=3.2$ for $50: 50$ and $\bar{M}_{w}=110.000 \mathrm{~g} / \mathrm{mol}, \mathrm{PDI}=$ 3.4 for 25:75. By comparing the SEC traces of the scaffolds before the degradation assays (Supporting Information, Fig. 1Sa, b, c) with those of the corresponding solutions immediately before electrospinning (Supporting Information, Figure 1Sd), it was possible to observe the occurrence of low molecular weight populations $(\sim 3000-5000 \mathrm{~g} / \mathrm{mol})$ in the electrospun scaffold. These findings indicate that the electrospinning process might induce some degradation during membrane preparation. SEC measurements of the blended scaffolds submitted to degradation clearly demonstrated an increase in the degradation profiles (Supporting Information, Figure 1Sa, b, c), which was related to the PLGA content added to the blend. An increase in low molecular weight populations $(\sim 3000-5000 \mathrm{~g} / \mathrm{mol})$ was observed after longer degradation periods, regardless of the ratio of the polymers in the membranes. The molecular weight decrease obtained by SEC after 10 weeks for PLLA/PLGA scaffolds at 75:25, 50:50, and 25:75 ratios was 33, 23 and 29\%, respectively (final apparent $\bar{M}_{w}$ of $113,000 \mathrm{~g} / \mathrm{mol}, 115,000 \mathrm{~g} / \mathrm{mol}$ and $78,000 \mathrm{~g} / \mathrm{mol}$, respectively). This polymer blend data showed intermediate degradation behavior compared to the original polymers, since the molecular weight was reduced with the mixture of a less dense polymer (PLGA). These findings indicate the major advantage of the proposed scaffold, which is the ability to manipulate de degradation time required for the implantable device through the correct blending of PLLA and PLGA. By the correct match, the degradation process of the polymeric scaffold can be speeded up or slowed down from months to weeks, as it is required for tympanic perforation treatments. As currently, the biomaterials used for tympanic perforation treatments are reabsorbed by the human body before perforation is restored, hindering the recovery process; the possibility to manipulate the degradation time of implantable biomaterials is a great step to successfully repair damaged tissues.

The evaluation of surface energy can supplement the characterization of PLLA:PLGA blends, once the balance between hydrophilic and hydrophobic interactions drives cell adhesion. The surface tension of a solid surface can be indirectly estimated from contact angle measurements and allows the prediction of wettability and other properties related to the surface of polymer mixtures [31]. The surface energy of spin-coated films from electrospun membranes is presented in Table 1. By applying the advancing contact angle measurements using water and diiodomethane as liquid tests, it is possible to evaluate the polar $\left(\gamma_{s}^{\mathrm{p}}\right)$ and dispersive $\left(\gamma_{\mathrm{s}}^{\mathrm{d}}\right)$ components to the surface tension of a solid surface $\left(\gamma_{s}\right)$, according to Wu's harmonic mean method [32,33]. The spin-coated films presented thicknesses in the range of 300-500 nm and surface tension values around $51 \mathrm{mN} / \mathrm{m}$; both results between the ones determined for the spin-coated films of pure PLLA or PLGA at the same concentration (Table 1). Previous work reported the same methodology to characterize PLLA electrospun fibers and found values of $76.3^{\circ}$ for water on PLLA films obtained by casting. The contact angle values determined for pure PLLA films were in the range of $80^{\circ}$ and agree with literature [34]. The sessile drop method was chosen in the sense that it may not give us the real surface tension values for the electrospun fibers, however it help us to verify the miscibility in the electrospun blends and compare their surface properties in general. Additional information about PLLA and PLGA thermal properties can be found in Supporting Information.

To finally decide which blend would be suitable for implantable devices, all polymer blends were subjected to an incubation, in which the samples, in their final form, were immersed in PBS solution and kept in humidified atmosphere containing $5 \% \mathrm{CO}_{2}$ at $37^{\circ} \mathrm{C}$ for 12 days (time required for production of epithelial tissue). The durability of each blend can be seen in Fig. 1.

As presented in Fig. 1a, the blend of PLLA/PLGA 75:25 remained unchanged over the period due low wettability and degradability. On the other end, the blend PLLA/PLGS 25:75 presented high degradation, showing erosion after 12 days, precluding its use. The polymer blend of PLLA/PLGA 50:50, showed in Fig. 1b, presented good durability, 
Table 1

Advancing contact angle, surface energy measurements, and thermal properties of electrospun membranes.

\begin{tabular}{|c|c|c|c|c|c|c|c|c|}
\hline \multirow[t]{2}{*}{ Sample } & \multicolumn{2}{|l|}{$\theta_{\mathrm{A}}\left({ }^{\circ}\right)$} & \multicolumn{3}{|c|}{ Surface energy $(\mathrm{mN} / \mathrm{m})$} & \multicolumn{3}{|c|}{ Thermal properties } \\
\hline & $\mathrm{H}_{2} \mathrm{O}$ & $\mathrm{CH}_{2} \mathrm{I}_{2}$ & $\gamma_{\mathrm{s}}$ & $\gamma_{\mathrm{s}}^{\mathrm{p}}$ & $\gamma_{s}^{d}$ & $\mathrm{~T}_{\mathrm{g}}\left({ }^{\circ} \mathrm{C}\right)$ & $\mathrm{T}_{\mathrm{c}}\left({ }^{\circ} \mathrm{C}\right)$ & $\mathrm{T}_{\mathrm{m}}\left({ }^{\circ} \mathrm{C}\right)$ \\
\hline PLLA & $80 \pm 1$ & $32 \pm 2$ & $51 \pm 1$ & $8 \pm 1$ & $44 \pm 1$ & 62.3 & n.o. ${ }^{\mathrm{a}}$ & 180.9 \\
\hline PLLA:PLGA (75:25) & $79 \pm 4$ & $36 \pm 2$ & $50 \pm 2$ & $8 \pm 2$ & $41 \pm 1$ & 62.7 & 105.1 & 179.2 \\
\hline PLLA:PLGA (50:50) & $79 \pm 1$ & $34 \pm 2$ & $51 \pm 1$ & $8 \pm 1$ & $43 \pm 1$ & 48.3 & 105.9 & 178.3 \\
\hline PLLA:PLGA (25:75) & $82 \pm 2$ & $32 \pm 1$ & $50 \pm 1$ & $7 \pm 1$ & $44 \pm 1$ & 42.6 & 104.2 & 176.2 \\
\hline PLGA & $80 \pm 1$ & $28 \pm 2$ & $53 \pm 1$ & $8 \pm 1$ & $45 \pm 1$ & 47.2 & n.o. ${ }^{\mathrm{a}}$ & n.o. \\
\hline
\end{tabular}

a n.o. not observed.

with the advantage of better hydration when compared to Fig. 1a, denoted by the translucence of the sample.

To complement the results, the mechanical properties of the electrospun mat of polymer blend 50:50 were evaluated via tensile test. The ultimate tensile strength was measured as $1.3 \pm 0.3 \mathrm{~N}$ and Young's modulus was $0.08 \mathrm{MPa}$, which means the biograft is a very soft material that could be easily deformed according to the anatomical needs of each patient. Surgically, there are two advances: first, a more flexible graft will help surgeon to conduct adjustment to anatomic anomalies that are quite frequent inside the external canal. And second, when it is refereed to sound mechanism of conductance, more elasticity represents better sound transmission through solid materials [6]. The Young's modulus of a human TM strip specimen was reported as 10$20 \mathrm{MPa}$. Some of these property values are often used as input to model sound transmission and hearing sensitivity in middle ear [35].

After characterization, the 50:50 blend of PLGA/PLLA showed the durability required for producing epithelial-equivalent tissue, which is at least 12 days. This membrane showed good wettability in culture medium and allowed the medium to pass through its pores for the transport of nutrients necessary for cell growth. For this reason, the 50:50 blend of PLGA/PLLA was chosen for further experiments.

\subsection{In vitro studies}

\subsubsection{Epidermis production}

The aim of this study was to build a biocompatible and bioabsorbable device that resembles a human tympanic membrane, consisting of 3 layers (skin, fibrous tissue and mucosa), to be implanted as an artificial graft for the recovery of tympanic membrane perforation.

For this purpose, fibroblasts and keratinocytes were seeded on the surface of electrospun polymeric membranes for the production of an epithelial equivalent tissue similar to that found in human tympanic membrane. After epithelial equivalent tissues were produced on electrospun membranes, the products were histologically evaluated to verify the interaction between the cells and the membrane. Cell cultures were also compared to samples of human tympanic membrane. The images obtained after staining with hematoxylin-eosin are shown in Fig. 2.

The morphology analysis revealed good interaction between the cells and the polymer scaffold, indicating good adhesion and cell proliferation. Fig. 2a and b show isolated cultures of fibroblasts and keratinocytes, respectively, on electrospun membranes. Fibroblasts interacted well with the membrane; the migratory capacity of these cells was demonstrated by the invasion of the porous structure, as expected for this cell type. Keratinocytes alone showed excellent adaptation and proliferation capacity. Even in isolated culture, it was possible to observe stratification up to two layers of cells; such stratification occurs in native human epithelium.

When a co-culture of fibroblasts and keratinocytes was performed, a synergy between cells occurred, showing both cell types together can develop and proliferate in a coordinated manner (Fig. 2c). Fibroblasts provided growth factors that controlled keratinocyte proliferation and differentiation and promoted stratification of the epithelium up to five cell layers. Fibroblasts maintained their migratory capacity through the membrane, providing a base for the anchoring and proliferation of keratinocytes. Among the laminated layers of keratinocytes, we noted a clear formation of the outer extract; the corneum layer is rich in keratin, indicating a complete differentiation of the epithelial equivalent tissue. The photomicrographs in Fig. 2b and c also show healthy cells with abundant cytoplasm and no vacuolization. A native human tympanic membrane (Fig. 2d) was used for comparison with the model developed in the laboratory (Fig. 2c). Both, mammals and artificial tympanic membrane showed a very similar epithelial layering. On the top of the human tympanic membrane there is a very large population of keratinocytes, while the fibroblasts are spread right below, within the tympanic fibrous layer [36]. The same cell distribution is found for the electrospun biomaterial, in which the keratinocytes are very well differentiated on the top layer, while the fibroblasts migrated to the electrospun scaffold mimicking the tympanic membrane fibrous layer.

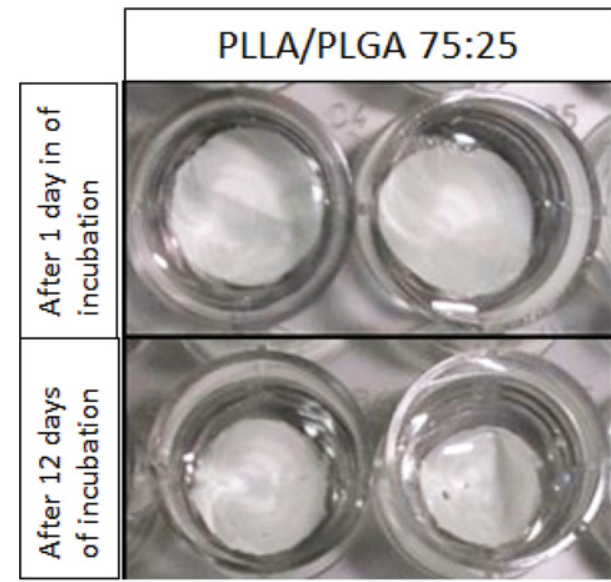

(a)

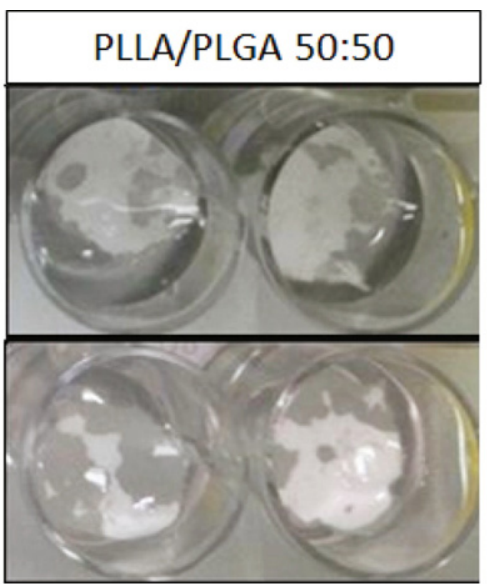

(b)

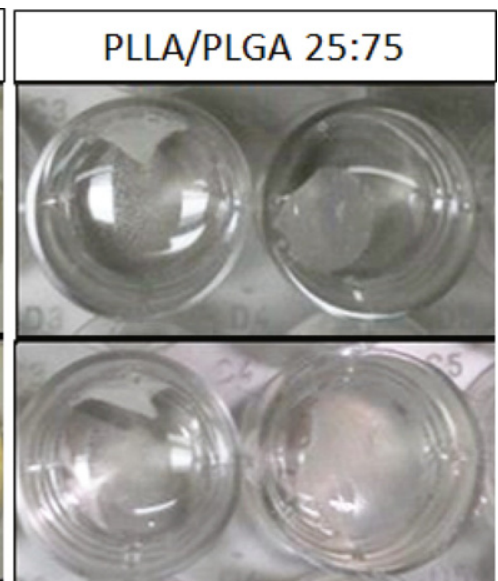

(c)

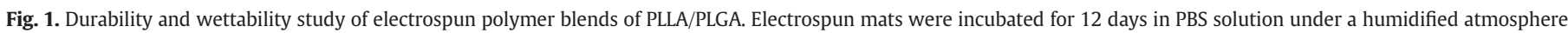
containing $5 \% \mathrm{CO}_{2}$ at $37^{\circ} \mathrm{C}$. 


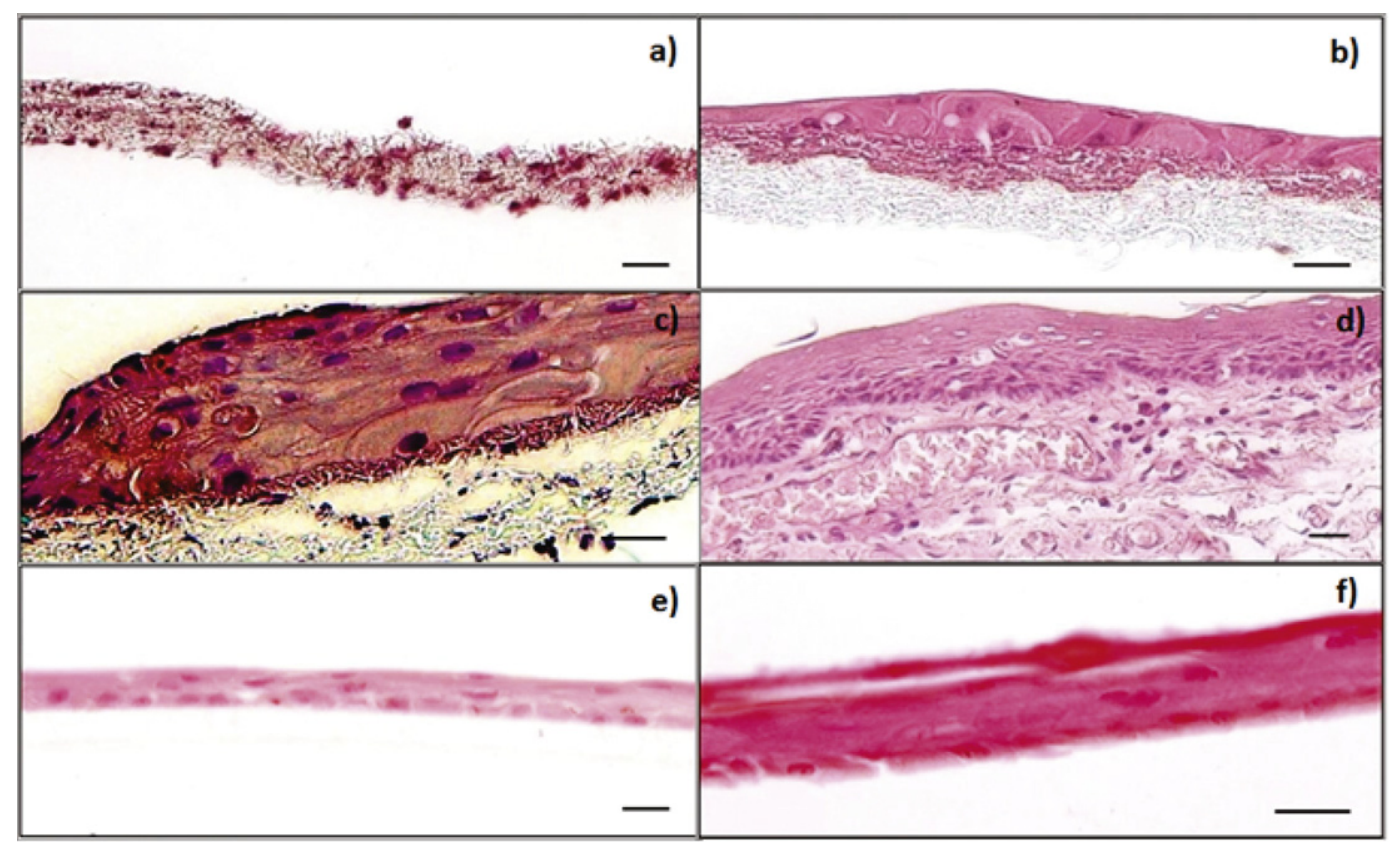

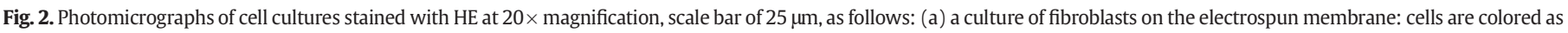

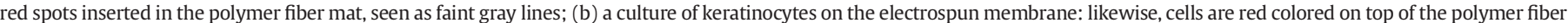

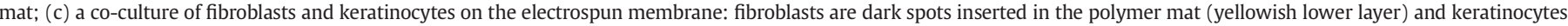

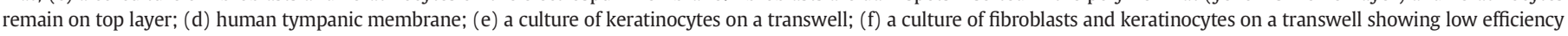
of stratification.

To evaluate the influence of the polymeric scaffold in the development of the epithelial-equivalent tissue, a culturing was performed directly in a transwell support, without the polymeric scaffold, for later comparison to cultures performed on scaffolds. The results are shown in Fig. 2e and $\mathrm{f}$, and they represent cell cultures of fibroblast and keratinocytes, respectively, seeded directly on the transwell; cell adhesion with low stratification efficiency was observed, indicating the presence of a scaffold is required for properly cell adhesion and growth. The production of an epithelial-equivalent tissue on the polymeric scaffold was enhanced when compared to the transwell culture. This finding indicates that the electrospun membrane offered a better scaffold for the anchoring of cells. In addition, this scaffold provided a porous three-dimensional structure; this facilitated cell migration, the flow of nutrients from the culture medium and the flow of growth factors released by the fibroblasts to developing cells.

Analysis on cell proliferation were conducted through immunohistochemistry for Ki-67. Fig. 3 is depicting the proliferative cells into the polymer both keratinocytes and fibroblasts (positive brown cell to KI67). Moreover, cells are well attached to the polymer, and it is possible also to observe the bright polymer fibers based on the birefringence of them. A fibroblast monolayer seeded on the polymer had offered a proper supporting the adhesion and differentiation of the keratinocyte. It is also possible to observe that keratinocytes are organized in stratified layers and are generating at least 5 cell layers, including a corneum strata (fibers on the top).

Unfortunately, the ECM proteins that are secreted by the cells are not easily analyzed probably for the low concentration that cells are secreting, however it is possible to see the polymer fibers.

Trypan Blue cell viability tests were performed to confirm the benign character of the membrane degradation products. The cell death rate was calculated using the Trypan Blue exclusion test. The results are presented in Fig. 4. The cytotoxicity assay revealed a 20\% reduction in the total number of cells when the culture medium used was first aged, being kept in contact with the electrospun scaffold for 35 days. This reduction is likely due to a local drop in $\mathrm{pH}$ caused by the high concentration of L-lactic acid and glycolic acid formed during the degradation of the membrane; this change in $\mathrm{pH}$ likely results in a decrease in cell proliferation. However, a death rate of $50 \%$ was not reached for this condition; therefore, it cannot be considered a toxic process. Considering that human body is a dynamic physiological system that is constantly restored, degradation products from the polymeric scaffold will be gradually resorbed without damage to cell proliferation and differentiation. These results are in agreement with all studies of biocompatibility of PLLA and PLGA, being these two degradable polyesters the predominant medical product for bioabsorbable sutures [37].

To date, complete studies on the degradation and absorption of biomaterials used in tissue engineering and medicine regenerative are rare. This study shows the polymeric scaffold presents no harmful products while degrading, which it is a matter of safety when considering absorbable biomaterials. Such information makes the artificial graft proposed a suitable candidate for implantable device, because the products from

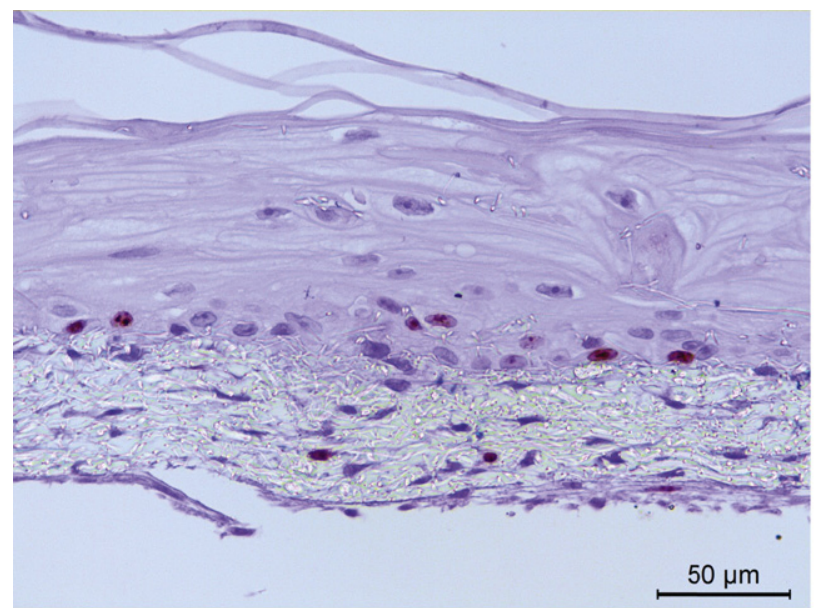

Fig. 3. Immunohistochemistry for Ki-67 of the artificial biograft, a co-culture of fibroblasts and keratinocytes grown on the polymeric blend PLLA/PLGA 50:50. 


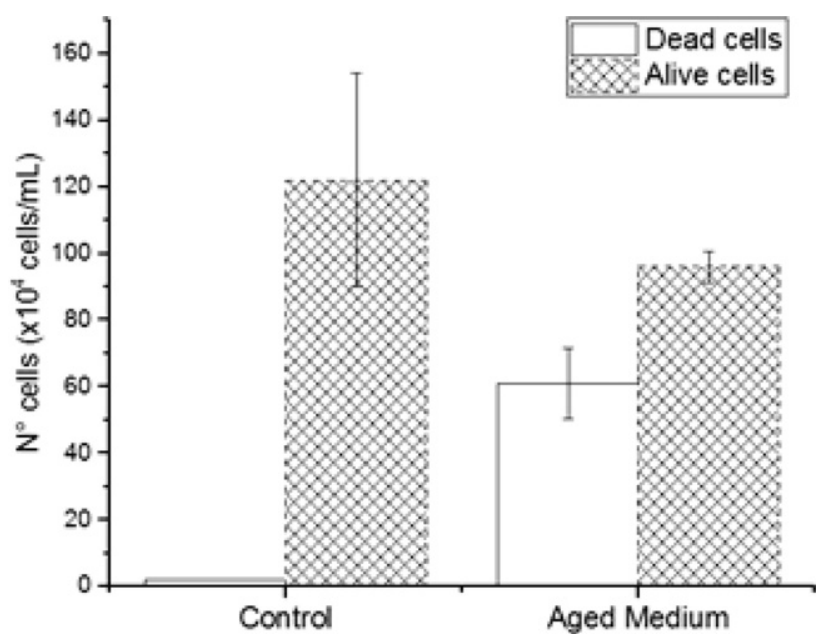

Fig. 4. Cytotoxicity test for cells cultured 24 hs in a medium aged for 35 days with polymeric electrospun membrane, using Trypan blue exclusion measurements. Normal D-10 medium was used as control.

the polymeric scaffold degradation, which are L-lactic acid and glycolic acid, are well known by human body metabolism being adsorbed and metabolized after tympanic membrane regeneration. This is an advantage when comparing to other biomaterials used as scaffolds to support the regeneration of tympanic membrane, including Gelfoam (device prepared from purified porcine skin gelatin), paper patch, and hyaluronic acid derivatives [26,38,39]. However, their biomechanical properties are non-optimal to the normal tympanic membrane, which may affect the long-term hearing function, being unsuitable for various types of perforation [40]. In addition to an inconsistent healing process, Gelfoam ${ }^{\circledR}$ presents no supportive effect at the regrowth of the tympanic membrane [41]. Currently, the use of Gelfoam ${ }^{\circledR}$ in the middle ear is avoided in view of a high probability for chronic inflammation, following hearing impairment. Paper patch has no clear benefits in tympanoplasty, with healing rates at about $50 \%$, compared to $80 \%$ when using normal temporal fascia [42]. Hyaluronic acid derivatives present about $80 \%$ of healing, results similar of the normal temporal fascia [43].

\subsection{In vivo studies}

The in vitro study demonstrated that polymeric scaffolds do not cause adverse effects on the cell type studied. Therefore, they can be used for implantable devices. The combination of fibroblasts and keratinocytes performed well in the reconstruction of an epithelialequivalent tissue; these cells acted synergistically to promote differentiation and the stratification of an epidermal equivalent. This construct was studied in vivo through myringoplasty performed on the right ear of adult male rats as a strategy for the recovery of perforated tympanic membranes. The experiment was performed with 15 rats divided into 3 groups (5 each) as described in Section 2.2.3.

The time for post-operative recovery was set at 4 weeks. The period of recovery for chronic tympanic perforation in rodents is undefined among researchers. Some authors define the period to close tympanic perforations in chinchillas as 6 weeks [22]. Studies by Maria et al. insist that tympanic perforation persists for 8 weeks after chronic intervention in rats [44]. Regardless, the aim of this study was to compare the spontaneous regeneration of iatrogenic perforated tympanic membrane in rats to the regeneration of tympanic membranes with epithelial equivalent implants. Therefore, the morphological examination of regenerated tissue was carried out over 4 weeks. The rats were sacrificed, and the new tympanic membranes were removed and processed for histological analysis. Table 2 summarizes the status of each rat 30 days after surgery.

According to Table $2,46 \%$ of the tympanic membranes that received no implant to assist recovery remained partially perforated. However, the tympanic membranes treated with different implants had $100 \%$ recovery. This already indicates that electrospun scaffolds covered with the epithelial-equivalent tissue have a positive influence on the regeneration of perforated tympanic membranes.

Fig. 5a,b show images from ear endoscopes performed before and after tympanic perforation, respectively. Fig. 5c,d,e,f,g,f show the pictures from ear endoscopies performed 4 weeks after surgery.

We observed initially that all of the perforated membranes used as control, which received no implants (Fig. 5c,e,g), showed uneven and partial healing. In the first example, observed in Fig. $5 c$, the membrane was extremely brittle and macroscopically monomeric (apparently with only one layer of the three existing layers within the tympanic membrane - mucus, epithelial and fibrous); the tympanic membrane also had a high chance of reperforation, which suggests a long-term risk of failure. In the second group of rats, observed in Fig. 5e, an intense granulation was observed in the perforation area along with a thickened and possibly dysfunctional tympanic membrane; such findings suggest that the sound transmission system is hindered. In the third group, observed in Fig. 5g, intense tympanosclerosis (intramembrane calcareous scarring) was evident; such scarring suggests anarchic and uncontrolled healing, with major damage to tympanic membrane functionality. In general, large tympanosclerosis processes affect hearing and results in diminished function.

In cases where a biograft implant was applied (with epithelialequivalent tissue), the macroscopic results were considerably better (Fig. 5d,f,h). We noted no evident tympanosclerosis or granulation on the site of the perforation, which means healing was uniform and accurate. In Fig. 5d, where the electrospun membrane was used as a graft; we noted a more natural, filled and not monomeric membrane with a high possibility that functionality was maintained. Fig. 5f, where the epidermal-equivalent device was implanted, revealed an absence of inflammatory responses harmful to tympanic membrane functionality and some vascularity. In Fig. $4 \mathrm{~h}$, where the epithelial-equivalent device was implanted, the macroscopic structure of the recovered tympanic membrane is completely normal and does not differ from a native tympanic membrane. It is also evident that tympanic membranes recovered with artificial graft stimuli healed macroscopically better, without apparent reaction processes, such as granulation, partial perforations or tympanosclerosis.

Fig. 6 shows histological micrographs taken from recovered tympanic membranes removed after in vivo studies. Fig. 6a,c,e show spontaneously regenerated membranes after perforation, and Fig. 6b,d,f show regeneration after of membranes after implantation of epithelial-equivalent biografts. Comparatively, there was an improvement in the quality of tissues formed after biograft implantation. This improvement means increased tissue volume, with an increased number of cells and stratified layers; the regenerated tympanic membrane was also more uniform, and irregular cell agglomerates were reduced.

The perforations that healed spontaneously without any biograft implantation, as observed in Fig. 6a,c,e, presented an irregular and less abundant tissue than the tissue formed by the biograft stimuli. This was also observed during the final surgery; tissues that had healed

Table 2

Status of rat tympanic membrane (TM) after 30 days of surgery (otoscopic data).

\begin{tabular}{|c|c|c|c|c|c|}
\hline \multirow{2}{*}{$\begin{array}{l}\text { Animal } \\
\text { Group }\end{array}$} & \multirow{2}{*}{$\begin{array}{l}\text { Number of } \\
\text { animals studied }\end{array}$} & \multicolumn{2}{|l|}{ Left TM } & \multicolumn{2}{|l|}{ Right TM } \\
\hline & & $\begin{array}{l}\text { Total } \\
\text { recovery }\end{array}$ & $\begin{array}{l}\text { Partial } \\
\text { recovery }\end{array}$ & $\begin{array}{l}\text { Total } \\
\text { recovery }\end{array}$ & $\begin{array}{l}\text { Partial } \\
\text { recovery }\end{array}$ \\
\hline 1 & 5 & 3 & 2 & 5 & 0 \\
\hline 2 & 5 & 1 & 4 & 5 & 0 \\
\hline 3 & 5 & 4 & 2 & 5 & 0 \\
\hline
\end{tabular}




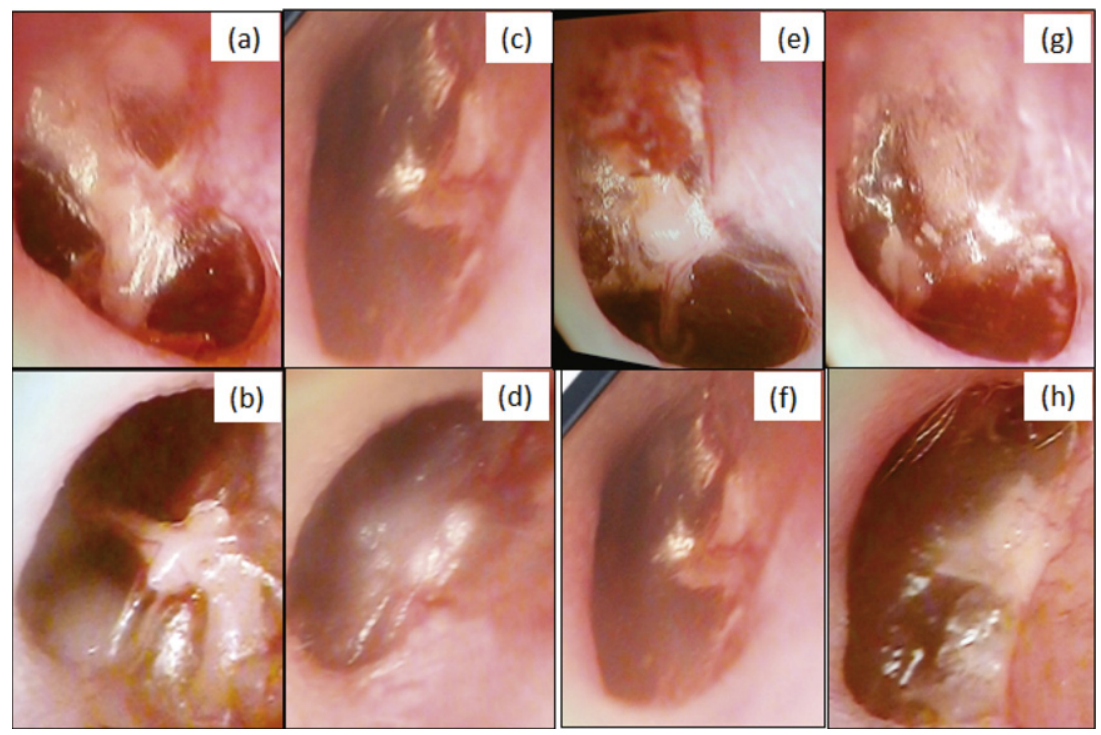

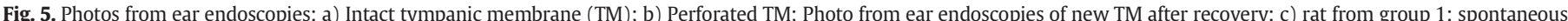

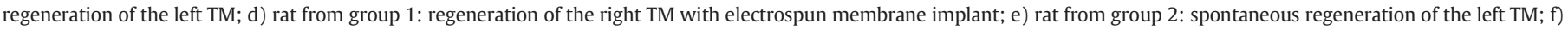

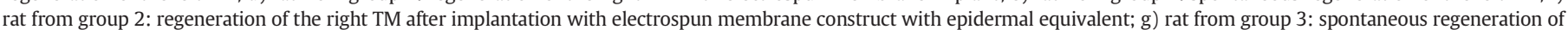
the left TM; h) rat from group 3: regeneration of the right TM after implantation with electrospun membrane construct with epithelial equivalent tissue.

spontaneously presented with inferior thickness and increased fragility during handling. This is most likely due to the fact that 3 layers of tympanic tissue (mucous, fibrous and epithelial layers) were not regenerated properly. It is possible that only the epidermal layer was regenerated. Fig. $6 \mathrm{f}$ shows a new tympanic membrane formed after the implantation of biografts containing epithelial-equivalent tissue. We observed more abundant regenerated tissue with a more uniform cell distribution without agglomerations. The formed tissue appeared to be noticeably healthy, thereby demonstrating the effectiveness of the implanted biograft.

To complement the histological analysis with hematoxylin-eosin staining, the immunostaining of new tympanic membrane was performed for the cytokeratin produced during keratinocyte differentiation. Figs. 7 and 8 present immunostaining images for cytokeratin 10 and cytokeratin 14 , respectively. The immunostaining assays show that the new tympanic membranes healed spontaneously are more keratinized than the membranes healed with the stimulus of the biograft implant. Keratin is a protein that provides impermeability and a protecting effect to the organism from the surrounding environment. Keratin is more highly expressed by epithelial cells under stress. This occurs during pathogen infection or when epithelium reconstitution is required. Keratin was expressed with greater intensity in spontaneous healing; this process was more aggressive due to the lack of a support, such as an implanted graft, for guidance. Therefore, a great epithelial

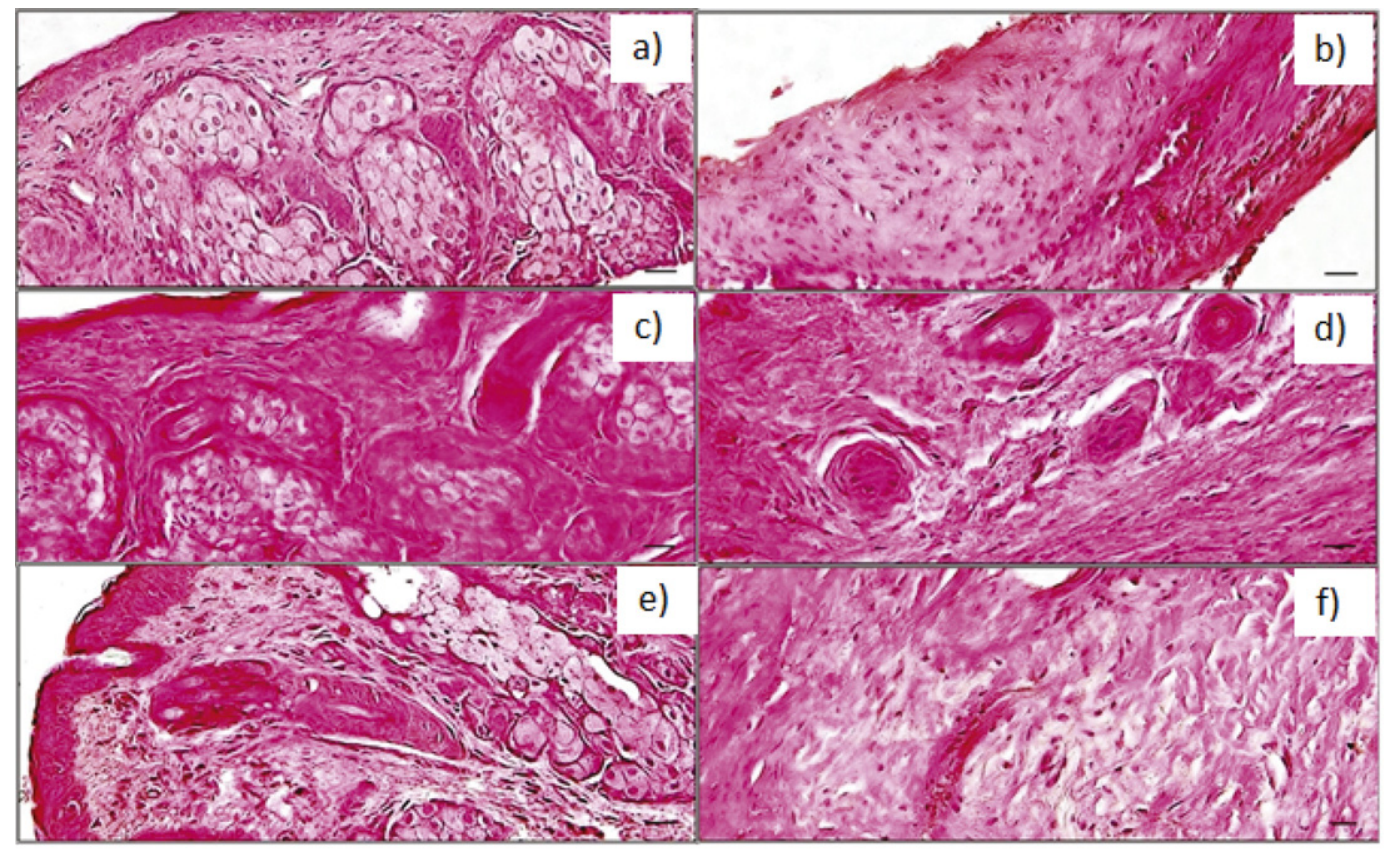

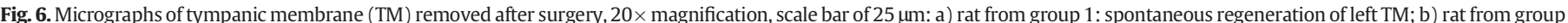

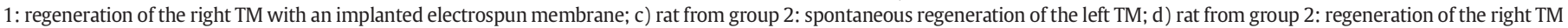

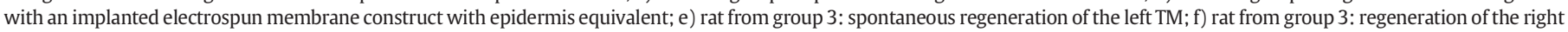
TM with an implanted electrospun membrane construct with epithelial equivalent tissue. 


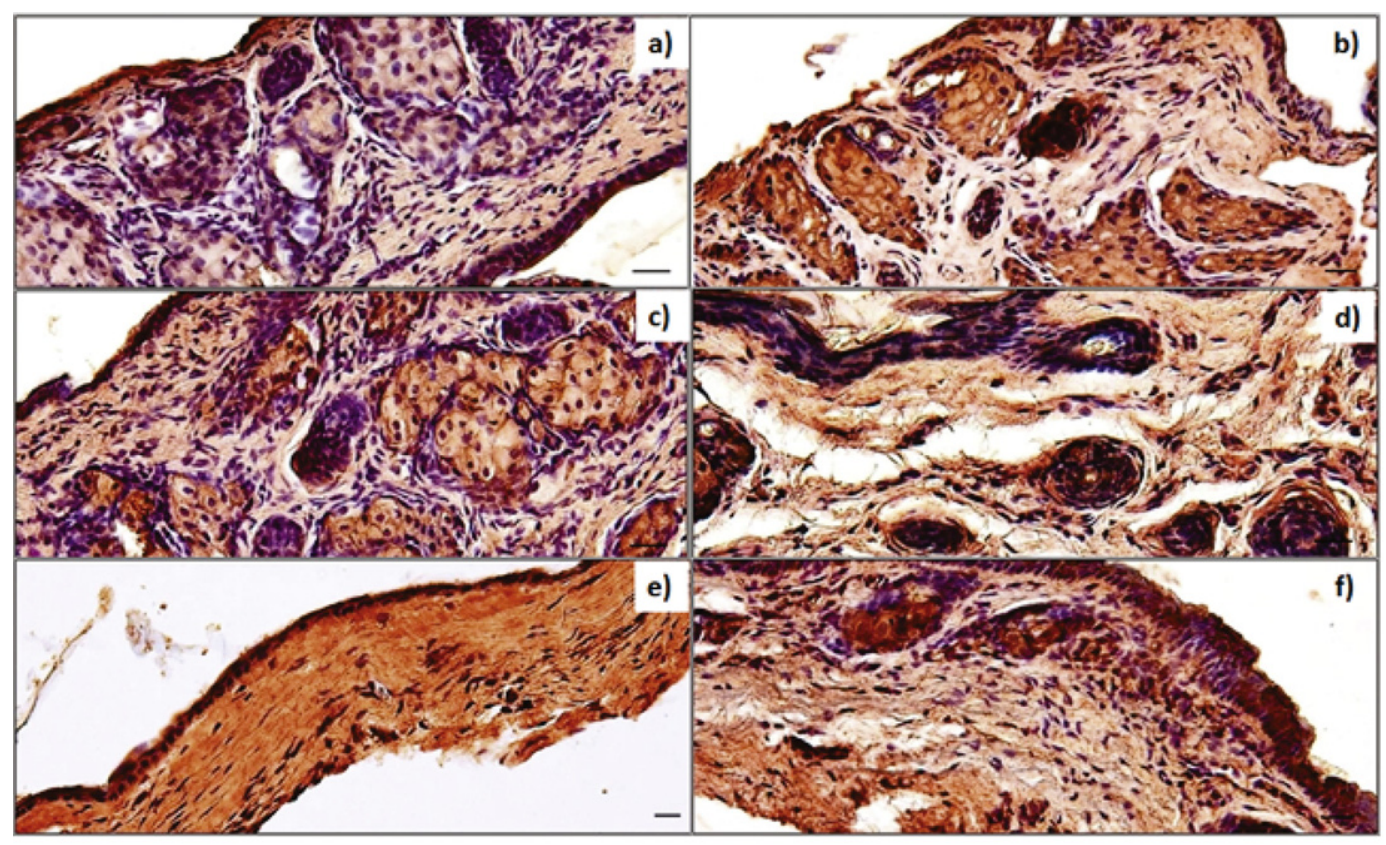

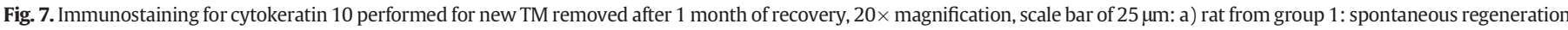

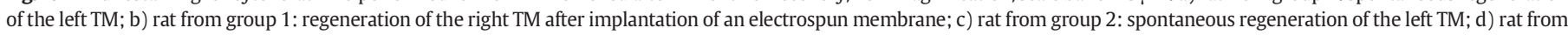

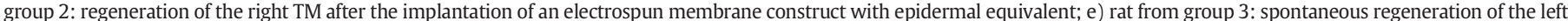
$\mathrm{TM}$; f) rat from group 3: regeneration of the right TM after implantation of an electrospun membrane construct with epithelial equivalent tissue.

remodeling process occurred. As already demonstrated in pathogenesis of the middle ear, greater keratinization of the tympanic membrane suggests poorer healing processes. Patients with chronic otitis media present with intense keratinization of the tympanic membrane are more predisposed to secondary cholesteatoma or multiple granulomas, which can cause new and serious diseases in the middle ear [45]. Tympanic membranes regenerated with the guidance of the biograft showed lower cytokeratin expression, as the graft facilitated the healing process. Lower keratinization indicates that neither the polymeric scaffold nor the cultured tissue increased the immune response of the organism, when compared to animals that received no biograft after perforation.

Grafts consisting of electrospun polymeric scaffolds and epithelialequivalent tissues promoted the recovery of tympanic membranes.

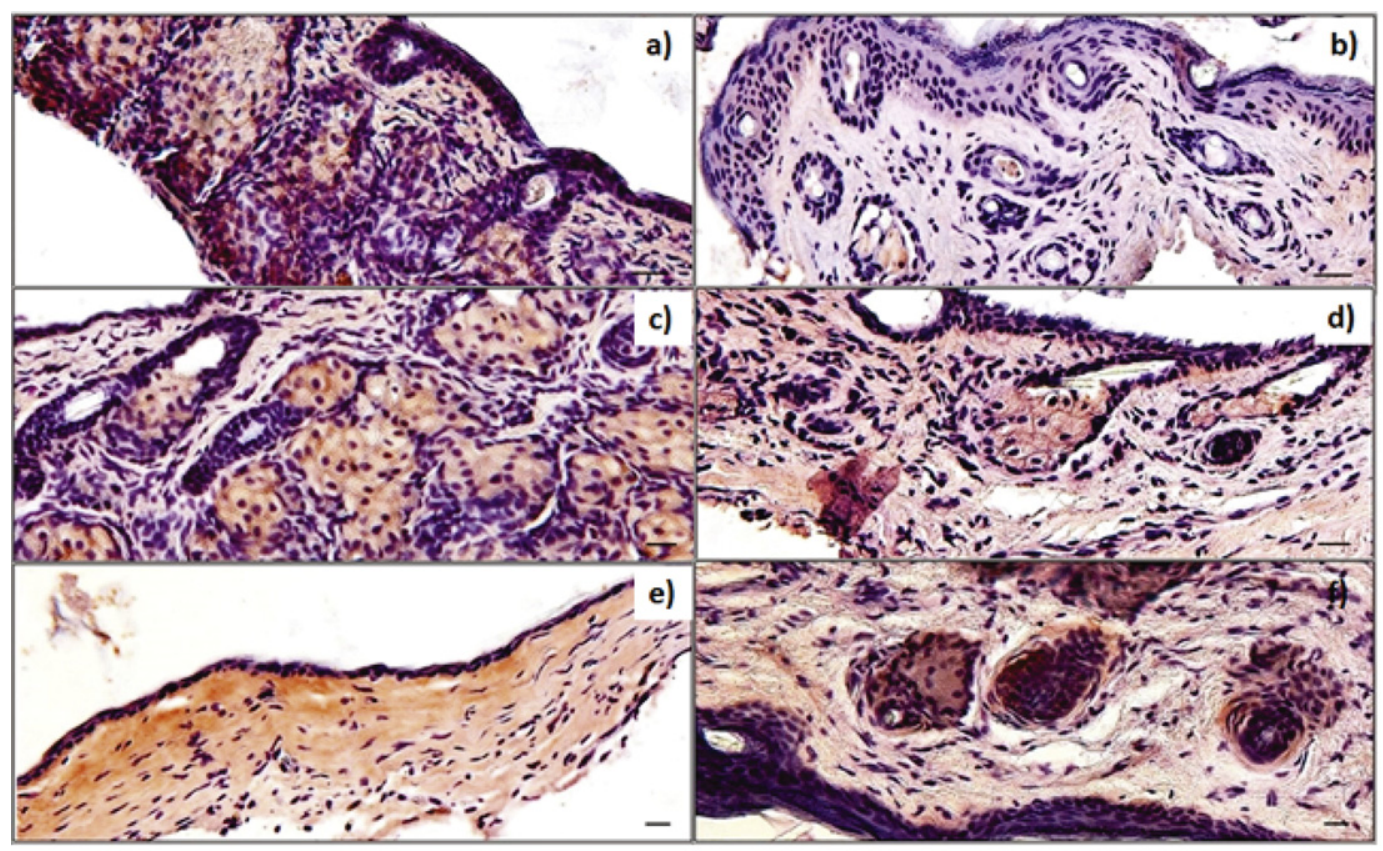

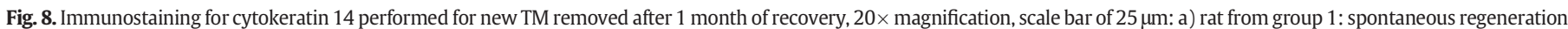

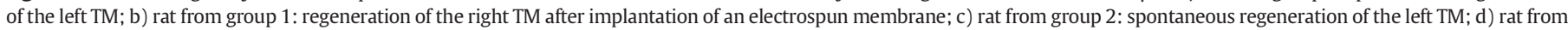

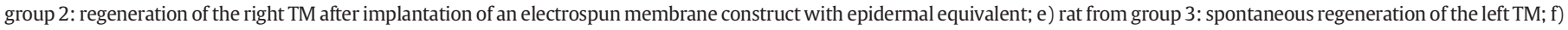
rat from group 3: regeneration of the right TM after implantation of an electrospun membrane construct with epithelial equivalent tissue. 
Uniform, healthy and abundant tissues with a regular distribution of cells were formed, and healing was less aggressive; what followed was a more natural and efficient healing process.

The artificial graft proposed in this study was particularly developed in attempting to satisfy the requirements of the perforated tympanic membrane healing processes. These requirements are compatibility, proper durability and the minimization side effects after myringoplasty. Side effects include cholesteatomas and granulomas, which appear due to intense reactions during the healing process. Moreover, the mechanical properties of the artificial graft helps the surgeon to better handle the artificial tissue during surgery to place the implant in the right position. The artificial tissue without the polymeric scaffold has no mechanical strength to be manipulated and it could be easily damaged before implantation.

\section{Conclusion}

In conclusion, our study described a new biograft created in attempting to fulfill the requirements of perforated tympanic membrane healing processes, which are compatibility, proper durability and less intense side effects following myringoplasty. The study also showed the polymer scaffold selected to support the graft presented no harmful products while degrading, which it is a matter of safety when considering absorbable biomaterials. The great advantaged of the biomaterials selected for the graft, which are PLLA and PLGA, is that the products of degradation, L-lactic acid and glicolic acid, are well known by human body metabolism being adsorbed and metabolized after tympanic regeneration, promoting no inflammatory response due to the unknown components. The results revealed that the biograft stimulated the formation of a regular neotympanum. Abundant regenerated tissue was produced, with uniform cell distribution, sharp stratification and without agglomerations. The formed tissue appeared healthy, possibly due to the less aggressive healing process, with a real possibility of maintaining its functionality.

\section{Acknowledgments}

The authors are grateful to FAPESP (Processes 2011/21442-6, 2011/ 18017-1 and 2011/22812-1) and CNPq (Processes 303030/2013-5 and 400145/2014-6) for funding this research. We are also grateful to Prof. Dr. Thomas Linder, Chairman of the Department of Otorhinolaryngology, Head \& Neck Surgery at Kantonsspital Luzern and Professor at Zürich University, Switzerland for his kind collaboration. We thank the Multiuser Analytical Laboratory of the Chemical Engineering and Food Engineering Department of the Federal University of Santa Catarina.

\section{Supplementary data}

Supplementary data to this article can be found online at http://dx. doi.org/10.1016/j.msec.2016.12.007.

\section{References}

[1] H. Kaftan, L. Reuther, B. Miehe, W. Hosemann, A. Beule, Inhibition of fibroblast growth factor receptor 1: influence on tympanic membrane wound healing in rats, Eur. Arch. Otorhinolaryngol. 269 (2012) 87-92

[2] H. Yasan, O. Erdogan, The effects of tympanic membrane perforation on bone conduction hearing level, Auris Nasus Larynx 39 (2012) 25-27.

[3] R.F. Bento, A. Miniti, S. Marone, Tratado de otologia, São Paulo, EDUSP, 1998

[4] R.F. Bento, M.M. Lessa, D. Chung, C. Wiikmann, A. Miniti, Condutas práticas em otologia, Fundação de Otorrinolaringologia, São Paulo, 2002.

[5] A. Pfammatter, E. Novoa, T. Linder, Can myringoplasty close the air-bone gap? Oto Neurotol 34 (4) (2013) 705-710.

[6] U. Fisch, J.S. May, T. Linder, Tympanoplasty, Mastoidectomy and Stapes Surgery, Thieme, New York, 2008.

[7] B. Levin, S.L. Redmond, R. Rajkhowa, R.H. Eikelboom, M.D. Atlas, R.J. Marano, Utilising silk fibroin membranes as scaffolds for the growth of tympanic membrane keratinocytes, and application to myringoplasty surgery, J. Laryngol. Otol. 127 (2013) S13-S20.
8] A.N. Acharya, H. Coates, D. Tavora-Vièira, G.P. Rajan, A pilot study investigation basic fibroblast growth factor for the repair of chronic tympanic membrane perforations in pediatric patients, Int. J. Pediatr. Otorhinolaryngol. 79 (3) (2015) 332-335.

[9] R.B. Garcia, M.M.M. Suárez-Varela, J.M.T. Conejeros, G.A. Porras, V.M. Puchades, J.D. Galofre, Miringoplastias. Un análisis retrospectivo de nuestros resultados, Acta Otorrinolaringol. Esp. 62 (3) (2011) 213-219.

[10] A. Jurado, M. Gil, T. Secall, D. Vadillo, M. Palau, M. Novoa, F. Massana, Miringoplastia: seguimiento auditivo y estudio de factores prognósticos, Acta Otorrinolaringol. Esp. 60 (03) (2009) 169-175.

[11] H. Wullstein, Theory and practice of tympanoplasty, Laryngoscope 66 (1956) 1076-1093.

[12] F.M. Rizer, Overlay versus underlay tympanoplasty part I: historical review of the literature, Laryngoscope 107 (1997) 1-25.

[13] S. Sarac, B. Gursel, H. Hermann, Use of homograft dehydrated temporal fascia in tympanoplasty, Otol Neurotol 23 (2002) 416-421.

[14] W.F. House, Miringoplasty. AMA Arch Otolaryngol 71 (1960) 399-404.

[15] A. Karkanevatos, S. De, V.R. Srinivansan, N.J. Roland, T.H.J. Lesser, Day-case miringoplasty: five year experience, J. Laryngol. Otol. 117 (2003) 763-765.

[16] B. Salen, Miringoplasty using septum cartilage, Acta Otolaryngol. Suppl. 188 (Suppl. 188) (1964) 82-91.

[17] C. Uçar, M. Kazkayasi, Simultaneous miringoplasty and septoplasty, and the use of nasal septal perichondrium, Eur. Arch. Otorhinolaryngol. 266 (2009) 1213-1217.

[18] J.R.O. Ramalho, Cicatrização de perfurações subagudas de membrana timpânica de chinchilas tratadas com fator de crescimento epitelial de pentoxifilina, Thesis (Doctor in Medicine: Otorhinolaryngology), School of Medicine, University of São Paulo, São Paulo, 2005.

[19] F. Rossi, M. Santoro, G. Perale, Polymeric scaffolds as stem cell carriers in bone repair, J. Tissue Eng. Regen. Med. 9 (10) (2015) 1093-1119.

[20] A. Kiziltay, A. Marcos-Fernandez, J.S. Roman, A. Sousa Rui, R.L. Reis, V. Hasirci, N. Hasirci, Poly(ester-urethane) scaffolds: effect of structure on properties and osteogenic activity of stem cells, J. Tissue Eng. Regen. Med. 9 (8) (2015) 930-942.

[21] S.B. Mahjour, F. Sefat, Y. Polunin, L. Wang, W. Hongjun, Improved cell infiltration of electrospun nanofiber mats for layered tissue constructs, J. Biomed. Mater. Res. A (2016)http://dx.doi.org/10.1002/jbm.a.35676.

[22] Y. Shen, S.L. Redmond, The BM, S. Yan, Y. Wang, L. Zhou, C.A. Budgeon, R.H. Eikelboom, M.D. Atlas, R.J. Dilley, M. Zheng, R.J. Marano, Scaffolds for tympanic membrane regeneration in rats, Tiss Eng Pt A 19 (5 and 6) (2013) 657-668.

[23] Y. Yaguchi, D. Murakami, M. Yamato, T. Hama, K. Yamamoto, H. Kojima, H. Moriyama, T. Okano, Middle ear mucosal regeneration with three-dimensionally tissue-engineered autologous middle ear cell sheets in rabbit model, J. Tissue Eng. Regen. Med. 10 (3) (2013) E188-E194.

[24] K.F. Farraro, K.E. Kim, S.L.-Y. Woo, J.R. Flowers, M.B. McCullough, Revolutionizing orthopaedic biomaterials: the potential of biodegradable and bioresorbable magnesiumbased materials for functional tissue engineering, J. Biomech. 47 (9) (2014) 1979-1986.

[25] T. Hama, K. Yamamoto, Y. Yaguchi, D. Murakami, H. Sasaki, M. Yamato, T. Okano, H. Kojima, Autologous human nasal epithelial cell sheet using temperature-responsive culture insert for transplantation after middle ear surgery, J. Tissue Eng. Regen. Med. (2015) http://dx.doi.org/10.1002/term.2012

[26] B.M. Teh, Y. Shen, P.L. Friedland, M.D. Atlas, R.J. Marano, A review on the use of hyaluronic acid in tympanic membrane wound healing, Expert. Opin. Biol. Ther. 12 (2012) 23-36.

[27] O.J. Lee, J.M. Lee, J.H. Kim, J. Kim, H. Kweon, Y.Y. Jo, C.H. Park, Biodegradation behavior of silk fibroin membranes in repairing tympanic membrane perforations, J Biomed Mater Res Part A 100A (2012) 2018-2026.

[28] H. Seonwoo, S.W. Kim, J. Kim, T. Chunjie, K.T. Lim, Y.J. Kim, S. Pandey, P.H. Choung, Y.H. Choung, J.H. Chung, Regeneration of chronic tympanic membrane perforation using an EGF-releasing chitosan patch, Tiss Eng Pt A 19 (17 and 18) (2013) 2097-2107.

[29] C.A. Brohem, L.B.S. Cardeal, M. Tiago, M.S. Soengas, S.B.M. Barros, S.S. Maria-Engler, Artificial skin in perspective: concepts and applications, Pigment Cell Melanoma Res 24 (1) (2011) 35-50.

[30] J.L. Dellacherie, Six surface characteristics of PLA and PLGA films, Appl. Surf. Sci. 253 (2006) 2758-2764.

[31] F. Garbassi, M. Morra, E. Occhiello, Polymer Surfaces: From Physics to Technology, Jonh Wiley \& Sons, New York, 1994

[32] J. Yahng, J. Bei, S. Wang, Enhanced cell affinity of poly(D,L-lactide) by combining plasma treatment with collagen anchorage, Biomaterials 23 (2002) 2607-2614

[33] R. Casarano, R. Bentini, V.B. Bueno, T. Iacovella, F.B.F. Monteiro, F.A.S. Iha, A. Campa, D.F.S. Petri, M. Jaffe, L.H. Catalani, Enhanced fibroblast adhesion and proliferations on electrospun fibers obtained from poly(isosorbide succinate-b-L-lactide) block copolymers, Polymer 50 (2009) 6218-6227.

[34] N.D. Luong, I.-S. Moon, Y.-K. Lee, J.-D. Nam, Surface modification of poly(L-lactide) electrospun fibers with nanocrystal hydroxyapatite for engineered scaffold applications, Mater. Sci. Eng. C 28 (2008) 1242-1249.

[35] H. Luo, S. Jiang, D.U. Nakmali, R.Z. Gan, H. Lu, Mechanical properties of a human eardrum at high strain rates after exposure to blast waves, J. dynamic behavior mater 2 (2016) 59-73

[36] M.M. Araújo, A.A.B. Murashima, V.M. Alves, M.C. Jamur, Hyppolito. Spontaneous healing of the tympanic membrane after traumatic perforation in rats, Braz J Otorhinolaryngol 80 (4) (2014) 330-338.

[37] T. Freier, Biopolyesters in tissue engineering applications, Adv. Polym. Sci. 203 (2006) 1-61.

[38] J.I. Abbenhaus, The use of reconstituted bovine collagen for tympanic membrane grafting, Otolaryngology 86 (1978) 485-487.

[39] A. Golz, D. Goldenberg, A. Netzer, M. Fradi, S.T. Westerman, L.M. Westerman, H.Z. Joachims, Paper patching for chronic tympanic membrane perforations, Otolaryngol. Head Neck Surg. 128 (2003) 565-570. 
[40] R. Aggarwal, S.R. Saeed, K.J. Green, Myringoplasty, J. Laryngol. Otol. 120 (2006) 429-432.

[41] A.J. Tahar, M. Hultcrantz, Healing of laser-induced tympanic membrane perforations in rats: no contribution of granulocyte colony-stimulating factor or Gelfoam, Int. J. Pediatr. Otorhinolaryngol. 76 (7) (2012) 963-968.

[42] S.N. Park, H.M. Kim, K.S. Jin, J.H. Maeng, S.W. Yeo, S.Y. Park, Predictors for outcome of paper patch myringoplasty in patients with chronic tympanic membrane perforations, Eur. Arch. Otorhinolaryngol. 272 (2) (2015) 297-301.
[43] M. Alzahrani, I. Saliba, Hyaluronic acid fat graft myringoplasty vs fat patch fat graft myringoplasty, Eur. Arch. Otorhinolaryngol. 272 (2015) 1873-1877.

[44] P.L.S. Maria, M.D. Atlas, R. Ghassemifar, Chronic tympanic membrane perforation: a better animal model is needed, Wound Repair Regen. 15 (2007) 450-458.

[45] L. Rüedi, Pathogenesis and surgical treatment of the middle ear cholesteatoma, Acta Otolaryngol. 361 (1979) 1-45. 